Давыдов В. М., Прохорец О. В., Языков В. А.

V. M. Davydov, O. V. Prokhorets, V. A. Yazykov

ПОДХОДЫ К МОДЕЛИРОВАНИЮ СОПРЯГАЕМЫХ ПОВЕРХНОСТЕЙ

СПЛАЙНАМИ

\title{
APPROACHES TO MODELING INTERFACING SURFACES WITH SPLINES
}

Давыдов Владимир Михайлович - доктор технических наук, профессор, зав. кафедрой «Технологическая информатика и информационные системы» Тихоокеанского государственного университета (Россия, Хабаровск); тел. 8(4212)375259. E-mail: davellut@mail.ru.

Mr. Vladimir M. Davydov - D.Sc. in Engineering, Professor, Head of the Engineering Computer Technologies and Information Systems Department at the Pacific National University (Russia, Khabarovsk); tel. 8(4212)37-52-59. E-mail: davellut@mail.ru.

Прохорец Ольга Вячеславовна - старший преподаватель кафедры информационных систем и технологий Хабаровского государственного университета экономики и права (Россия, Хабаровск); тел. 8(4212)76-54-58. E-mail: olga prokhorets@mail.ru.

Ms. Olga V. Prokhorets - Senior Lecturer of the Information Systems and technologies Department at the Khabarovsk State University of Economics and Law (Russia, Khabarovsk); tel. 8(4212)76-54-58. E-mail: olga_prokhorets@mail.ru.

Языков Вячеслав Андреевич - кандидат технических наук, доцент кафедры «Технологическая информатика и информационные системы» Тихоокеанского государственного университета (Россия, Хабаровск); тел. +79145488228. E-mail: jva0117@mail.ru.

Mr. Vyacheslav A. Yazykov - Ph.D in Engineering, Associate Professor of the Engineering Computer Technologies and Information Systems Department at the Pacific National University (Russia, Khabarovsk); tel. 8-914-548-82-28. E-mail: jva0117@mail.ru.

Аннотация. В статье представлены результаты работы по моделированию сопрягаемых поверхностей сплайнами для дальнейшего использования в инженерном анализе методом конечных элементов. На основе принципа суперпозиции процесс моделирования контактного взаимодействия поверхностей разделён на два уровня: уровень моделирования волнистости и уровень моделирования шероховатости.

Summary. This article presents the results of the modelling interfacing surfaces with splines fit for further use in finite element engineering analysis. The process of modeling interfacing surfaces is divided into two levels based on the superposition principle: the level of modelling waviness and the level of modelling roughness.

Ключевые слова: волнистость и шероховатость поверхностей, геометрическое моделирование поверхностей, сплайны, метод конечных элементов.

Key words: waviness and roughness of surfaces, geometric modeling, spline, the finite element method.

УДК 620.179:621.891

Свойства контактирующих поверхностей являются существенным фактором, влияющим на весь набор показателей качества технологического оборудования. Они влияют на точность, виброустойчивость, динамическую устойчивость, долговечность, надёжность, себестоимость и пр.

В процессе проектирования технологического оборудования с целью оценки ожидаемой точности необходим анализ состояния сопрягаемых поверхностей как неподвижных, так 
Давыдов В. М., Прохорец О. В., Языков В. А.

ПОДХОДЫ К МОДЕЛИРОВАНИЮ СОПРЯГАЕМЫХ ПОВЕРХНОСТЕЙ СПЛАЙНАМИ

и подвижных соединений. Для оценки динамической устойчивости технологической системы при построении математических моделей необходима информация о демпфирующей способности стыков. Метод конечных элементов (МКЭ) даёт возможность рассчитать сложную систему. Однако расчёты МКЭ сложных сборок ведутся без учёта контактных взаимодействий, которые в действительности в значительной степени формируют и статические, и динамические свойства технологической системы.

Цель работы - создание методики описания параметров шероховатости и волнистости поверхности, адекватно отражающей реальное состояние поверхности для расчёта и оценки состояния сопрягаемых поверхностей при различных влияниях внешней среды.

Для достижения цели были поставлены следующие задачи:

- разработать методику аппроксимации сопрягаемых поверхностей с возможностью оценки точности приближения;

- установить отличительные особенности взаимосвязей пространственного распределения шероховатости и волнистости;

- разработать программное обеспечение подготовки массива данных для создания пространственных форм волнистости с заданными характеристиками; сплайнов.

- разработать геометрические модели шероховатости и волнистости с использованием
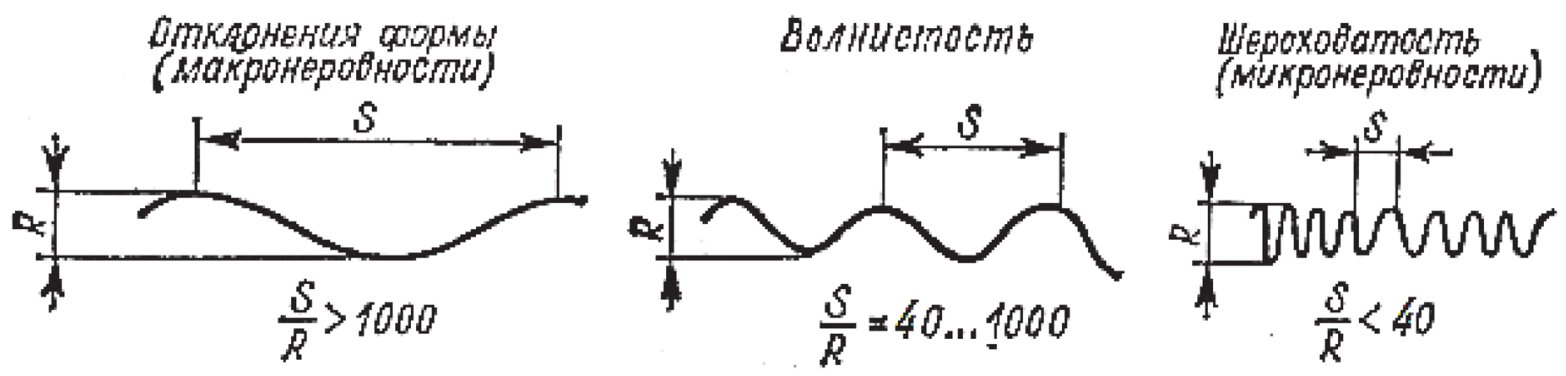

Рис. 1. Параметры волнистости

Контактные взаимодействия носят нелинейный характер и зависят в первую очередь от погрешностей геометрии контактирующих поверхностей, которые можно разделить на отклонения формы (макронеровности), волнистость и шероховатость (микронеровности) [1].

Отклонения формы связаны с общей геометрией контактирующих поверхностей и, как правило, регламентируют конкретные отклонения (неплоскостность, отклонение от круглости и т.п.). Параметры волнистости установлены рекомендацией РС 3951-73 (см. рис. 1). Параметры шероховатости установлены ГОСТ 2789-73 «Шероховатость поверхности. Параметры и характеристики». Наиболее полно представлены характеристики изделий, структура поверхности в ГОСТ Р ИСО 4287-2014.

Границу между волнистостью и шероховатостью проводят условно, и к волнистости относят неровности, у которых соотношение шага к высоте больше 40 (см. рис. 2) [1].

Рассмотрим возможность моделирования контактирующих поверхностей разработанными в системах САПР средствами описания геометрии поверхностей [2]: полигональными и сплайновыми моделями.

Полигональная модель представляет собой многогранную поверхность, составленную из плоских граней в виде прямоугольных треугольников с примерно равными катетами. Файл описания для разных систем геометрического моделирования САПР такой поверхности для участка 1 мм $^{2}$ имеет размеры: в КОМПАС $-80.4 \mathrm{Mb}$; в обменном файле формата STEP - $110 \mathrm{Mb}$; в SolidWorks - $123 \mathrm{Mb}$.

Для полигональной модели моделируемая поверхность наиболее адекватна реальной поверхности. Среднее отклонение для площадки 0,5×0,5 мм составило -1,56974Е-13 
(-6,71961Е-05 без удаления тренда). Моделирование шероховатости полигональными поверхностями использовано в работах [3 - 5].

NURBS-поверхность по «сети точек» может быть построена двумя видами кривых: CV-кривые и Р-кривые.

CV-кривые (control vertices curves). Форма таких кривых задаётся управляющими вершинами (полюсами), лежащими на вспомогательной кривой. Управляющие вершины NURBS воздействуют на локальную область, размером которой можно управлять, используя вес полюса (коэффициент степени влияния). Эти поверхности не требуют больших вычислительных ресурсов, но моделируемая поверхность не адекватна реальной поверхности. Оценка несоответствия отклонения по нормали к плоскости параметрического аргумента UV aппроксимирующей функции максимальным и средним значениями зависит от степени аппроксимируюшего полинома и веса полюса. При моделировании полиномом четвёртой степени в обоих направлениях UV и весе полюсов, равном единице участка поверхности размером 1 мм $^{2}$, обработанного шлифованием с шероховатостью $\mathrm{Ra} 0.5$, отклонение составило: среднее 0,000378846 мм; максимальное 0,00402811 мм. Для степени полинома, равной пяти, отклонения составили: среднее 0,000375556 мм; максимальное 0,00399932 мм. Улучшение составило: для среднего отклонения на $0,87 \%$; для максимального - 0,7 \%. При этом средняя высота микронеровностей - 0,00005 мм.

\begin{tabular}{|c|c|c|c|c|c|c|c|c|c|}
\hline \multirow{2}{*}{$\begin{array}{c}\text { Paccmogнue } \\
\text { Mexrdy } \\
\text { неров̈носmями, } \\
\text { нкM }\end{array}$} & \multicolumn{9}{|c|}{ 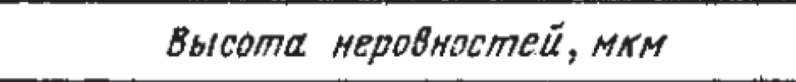 } \\
\hline & $0-1$ & $1-2 \cdot 2-4$ & $|4-8|$ & $8-16$ & $\begin{array}{l}16- \\
32\end{array}$ & {$\left[\begin{array}{l}39 \\
6\end{array}\right.$} & $\begin{array}{l}64- \\
128\end{array}$ & $\begin{array}{l}128 \\
256\end{array}$ & $\begin{array}{l}256 \\
500\end{array}$ \\
\hline \multicolumn{10}{|l|}{$0-1$} \\
\hline \multicolumn{10}{|l|}{$1-2$} \\
\hline \multicolumn{10}{|l|}{$2-4$} \\
\hline \multicolumn{10}{|l|}{$4-8$} \\
\hline \multicolumn{10}{|l|}{$8-1 \overline{6}$} \\
\hline \multicolumn{10}{|l|}{$16-32$} \\
\hline \multirow{2}{*}{\multicolumn{10}{|c|}{$\frac{32-64}{64-128}$}} \\
\hline \\
\hline & & & & & & & & $\frac{128-256}{256-500}$ & \\
\hline \multicolumn{10}{|l|}{$500-1000$} \\
\hline \multicolumn{10}{|l|}{$1000-2000$} \\
\hline \multicolumn{10}{|l|}{$0000-4000$} \\
\hline \multirow{2}{*}{\multicolumn{10}{|c|}{$\frac{4000-8000}{8000-16000}$}} \\
\hline & & & $D$ & & & & & & \\
\hline \multicolumn{10}{|l|}{$16000-32000$} \\
\hline \multicolumn{10}{|l|}{$64000-128000$} \\
\hline \multicolumn{10}{|l|}{$128000-256000$} \\
\hline $256000-500000$ & & & & & & & & & \\
\hline
\end{tabular}

Рис. 2. Граница между волнистостью и шероховатостью

P-кривые (point curves). Форма таких кривых задаётся вершинами, лежашими непосредственно на самой кривой (управляющие точки Безье). Управляющие точки Безье влияют сразу на всю поверхность. Эти поверхности требуют больших вычислительных ресурсов (памяти и времени обработки). Построение поверхностей выполняется по «пласту точек» или «сети точек», последнее отличается тем, что точки поверхности должны располагаться рядами, содержащими одно и то же количество точек. Это даёт возможность применять этот инструмент для упорядоченного расположения точек на регулярной координатной сетке с равномерным шагом. 
Давыдов В. М., Прохорец О. В., Языков В. А.

ПОДХОДЫ К МОДЕЛИРОВАНИЮ СОПРЯГАЕМЫХ ПОВЕРХНОСТЕЙ СПЛАЙНАМИ

Сформированная база данных шероховатостей поверхностей на основе 3D-микрометрии сканированием набора образцов (эталонов) шероховатостей с помощью информационно-измерительного комплекса [6] содержит данные для площадок размерами $1 \times 4$ мм. В базе находятся данные эталонов для фрезерования, строгания и шлифования Ra в пределах $0,45 \ldots 5,95$. Это соответствует диапазону $\mathrm{Rz} 1,6 \ldots 40$ мкм.

Информативность исходных данных, по причинам технических возможностей применяемых устройств, уменьшается из-за выпадения из рассмотрения большого количества точек измерения:

1. Так как расстояние между трассами измерений не может быть меньше 0,005 мм изза особенностей прибора, а вдоль трассы расстояние между точками измерений составляет менее 1 мкм, то для формирования регулярной сетки с одинаковым шагом в обоих направлениях из массива точек вдоль трассы делается выборка с пропуском определённого количества точек. Количество пропускаемых точек зависит от выбранного расстояния между трассами.

2. Общее максимальное количество точек, составляющих «пласт точек», из-за возможностей используемых приложений САПР не превышает 40200.

С учётом этих ограничений по данным эталонов базы сформированы «сети точек» для участков моделирования шероховатостей.

На основе принципа суперпозиции процесс моделирования контактного взаимодействия поверхностей разделён на два уровня: уровень моделирования волнистости и уровень моделирования шероховатости.

Для моделирования шероховатости в работе используется построение шероховатых поверхностей по «сети точек» на основе Р-кривых по данным базы шероховатостей.

На рис. 3 показаны модели шероховатых поверхностей, сформированные в системе KOMПАС: a - фрезерование Ra 8,0; б - фрезерование Ra 0,63; в - шлифование Ra 0,50. Ширина областей сканирования устанавливалась с учётом шероховатости поверхностей и составила 1 мм для поверхностей с шероховатостями менее Ra 2,5, для анализа поверхностей с большей шероховатостью ширина области сканирования увеличена больше базовой длины (2,5 мм) за счёт увеличения шага между трассами в четыре раза.

a)

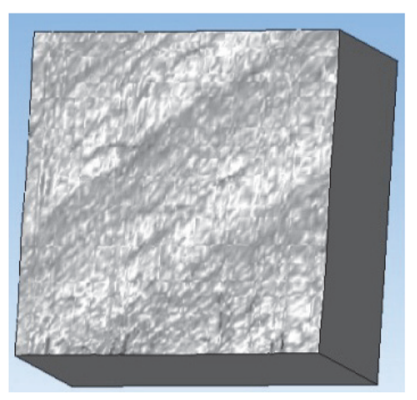

б)

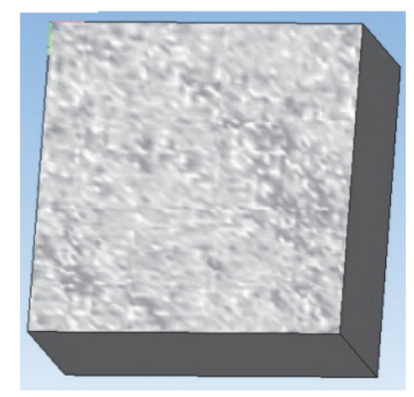

в)

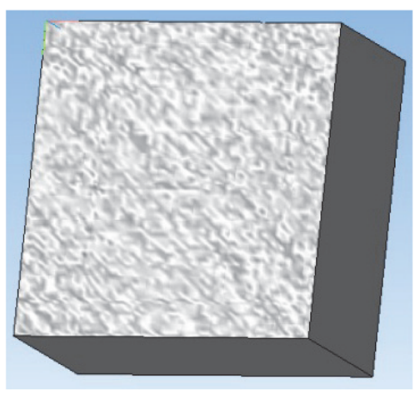

Рис. 3. Модели поверхностей

При моделировании волнистости, согласно стандарту РС 3951-73, высота волнистости $W_{Z}$ находится как среднее арифметическое из пяти значений $(W 1 \ldots W 5)$, определённых на длине участка измерения $L w$, равного пяти действительным наибольшим шагам $S w$ волнистости (см. рис. 4, a).

Средний шаг волнистости $S_{W}$, мм, - среднее арифметическое значений длин отрезков $S_{W i}$ средней линии, ограниченных точками их пересечения с соседними участками профиля волнистости (см. рис. 4, б). 


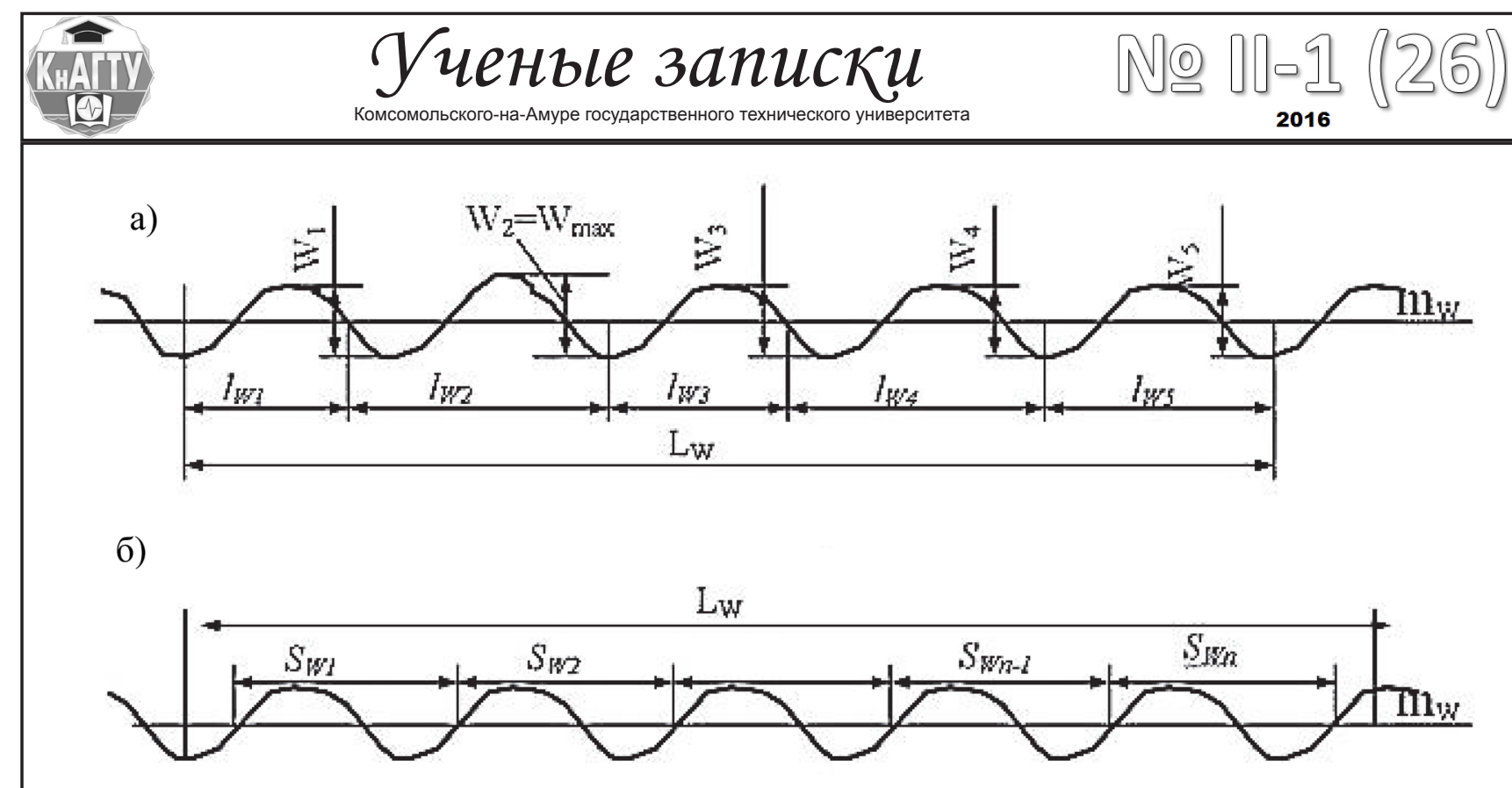

Рис. 4. Схема определения высоты (а) и шага (б) волнистости

Волнистость моделируется сплайновыми поверхностями с учётом рекомендаций (см. рис. 2). При этом значения $W_{Z}$ принимаются равными высотам, а $S_{W}-$ расстояниям между неровностями.

Для формирования «сети точек» волнистостей разработана программа CL-Ver. Ocoбенность сети точек для волнистости, сформированной программой, заключается в том, что координаты $Z$ вершин сплайнов в каждом координатном направлении образуют последовательность с чередованием значений: $A_{\min }$ и $A_{\max }$, где $A_{\min }-$ минимальное значение волны и в программе по умолчанию принято $A_{\min }=0 ; A_{\max }$ - максимальное значение волны, вводится в программе для формирования волнистости.

Значения $A_{\min }$ и $A_{\max }$ описывают высоту волнистости, мм,

$$
W_{z}=A_{\text {max }}-A_{\text {min }} \text {. }
$$

Расстояния между неровностями вводятся как длины волн отдельно для каждого координатного направления.

На рис. 5 показана модель образца с волнистостью. Из-за особенностей процессов визуализации в разных системах САПР изображения моделей могут отличаться от действительных описаний математических моделей.

a)

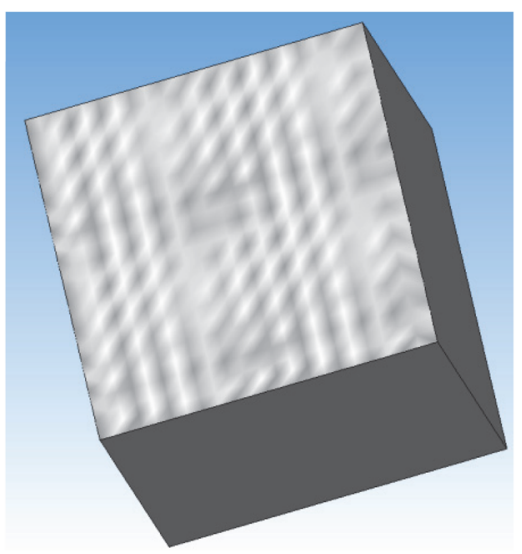

б)

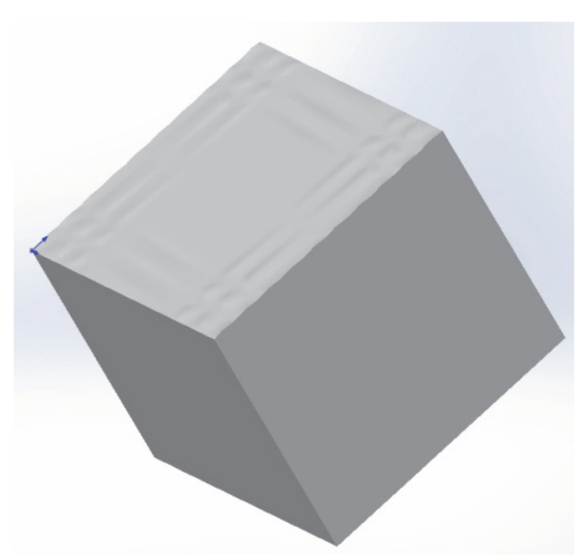

Рис. 5. Визуализация модели: а - в КОМПАС; б - в SolidWorks 
Особенностью сплайновых поверхностей является отсутствие острых углов, которые при контактном взаимодействии являются существенными концентраторами напряжений. Можно допустить, что условия взаимодействия сплайновых поверхностей аналогичны контактному взаимодействию выпуклых поверхностей в классической постановке Герца [7].

У сплайна Безье (см. рис. 6) высота каждой вершины оказывает влияние на форму сплайна в целом. Высота крайних волн сплайна отличается от высот срединных волн. Это связано с кривизной крайних участков сплайна. Для обеспечения гладкости сопряжения для двух соседних участков установлено условие равенства производных первого порядка. Для крайних участков этого условия нет, т.к. нет сопряжённых участков. Управлением кривизной крайних участков, примыкающих к крайним вершинам, можно выровнять высоту волн на этих участках. Для формулировки математического описания задачи контактного взаимодействия сплайновых поверхностей выбирается участок, удалённый от концов сплайна. Для выделенного участка сплайна на рис. 6 базовая функция описывается полиномом третьей степени

$$
y=a_{0}+a_{1} x+a_{2} x^{2}+a_{3} x^{3} .
$$

Приняв $x=0, y=0$ и $x=S_{W}, y=W_{Z}$ и допустив, что первые производные в точках экстремумов равны нулю, найдём

$$
a_{0}=0, \quad a_{1}=0, \quad a_{2}=3 \frac{W_{Z}}{S_{W}^{2}}, \quad a_{3}=-2 \frac{W_{Z}}{S_{W}^{3}} .
$$

Уравнение, описывающее линию между двумя точками сплайна при принятых допущениях

$$
y=3 \frac{W_{Z}}{S_{W}^{2}} x^{2}-2 \frac{W_{Z}}{S_{W}^{3}} x^{3} .
$$

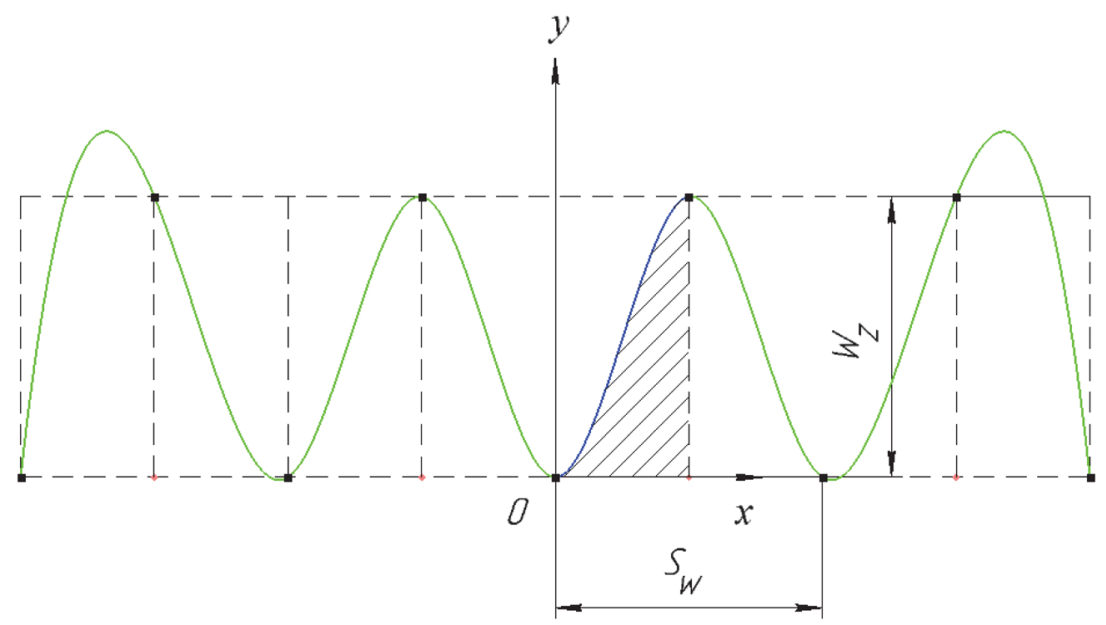

Рис. 6. Сплайн Безье

Полученное уравнение описывает форму индентора [8; 9] которое используется для верификации сплайновых моделей при определении контактных напряжений и перемещений методом конечных элементов.

Выводы:

1. Разработана методика аппроксимации сопрягаемых поверхностей с учётом их шероховатости и волнистости на основе сплайнов.

2. Разработано программное обеспечение формирования массива данных для моделирования сплайнами волнистых поверхностей с заданными параметрами.

3. Предложена математическая модель формы индентора в виде сплайна. 
ЛИТЕРАТУРА

1. Демкин, Н. Б. Качество поверхности и контакт деталей машин / Н. Б. Демкин, Э. В. Рыжов. - М.: Машиностроение, 1981. - 248 с.

2. Голованов, Н. Н. Геометрическое моделирование / Н. Н. Голованов. - М.: Изд-во физикоматематической литературы, 2002. - 472 с.

3. Ольшевский, А. А. Разработка методики решения контактных задач с учётом шероховатости поверхностей / А. А. Ольшевский // Молодежн. науч.-техн. конф. техн. вузов центральной России: тезисы докладов / ред. О. А. Горленко. - Брянск: БГТУ, 2000. - С. 63-67.

4. Ольшевский, А. А. Решение контактных задач с учётом шероховатости поверхностей контакта методом конечных элементов с использованием трёхмерных расчётных схем / А. А. Ольшевский // Динамика, прочность и надёжность транспортных машин: сб. науч. тр. - Брянск: БГТУ, 2002. С. 149.

5. Ольшевский, А. А. Методика решения контактных задач для тел произвольной формы с учётом шероховатости поверхности методом конечных элементов: дис. ... канд. тех. наук: $01.02 .06 /$ Ольшевский Александр Алексеевич. - Брянск, 2003. - 121 с.

6. Давыдов, В. М. Информационно-измерительный комплекс 3D-метрии шероховатости поверхности / В. М. Давыдов, О. В. Прохорец, В. А. Языков // Вестник Брянского государственного технического университета. - 2015. - № 2 (46). - С. 104-109.

7. Hertz. On the Contact of Elastic Solids. - London: Miscellaneous Papers. McMillan, 1896. - Pp. 146-183.

8. Sneddon, I. N. The Relation between Load and Penetration in the Axisymmetric Boussinesq Problem for a Punch of Arbitrary Profile. - Int. J. Eng. Sci.: Pergamon Press, 1965. - Vol. 3. - Pp. 47-57.

9. Попов, В. Л. Механика контактного взаимодействия и физика трения. От нанотрибологии до динамики землетрясений / В. Л. Попов. - М.: Физматлит, 2013. - 352 с. 